\title{
Civil Partnership Dissolved
}

National Cancer Institute

\section{Source}

National Cancer Institute. Civil Partnership Dissolved. NCI Thesaurus. Code C150736.

Indicates that a civil partnership has been legally dissolved. 